\title{
Proportion of new HIV infections attributable to herpes simplex 2 increases over time: simulations of the changing role of sexually transmitted infections in sub-Saharan African HIV epidemics
}

\author{
Esther E Freeman, Kate K Orroth, Richard G White, Judith R Glynn, Roel Bakker, Marie-Claude Boily, \\ Dik Habbema, Anne Buvé, Richard J Hayes
}

Sex Transm Infect 2007;83(Suppl I):i17-i24. doi: 10.1136/sti.2006.023549

See end of article for authors' affiliations

Correspondence to: Dr Esther E Freeman, Harvard Medical School Francis Weld Peabody Society, 260 Longwood Ave, Boston, MA 02115, USA: esther_freeman@hms. harvard.edu

Accepted 18 March 2007 Published Online First

3 April 2007

\begin{abstract}
Objective: To understand the changing impact of herpes simplex 2 (HSV-2) and other sexually transmitted infections (STIs) on HIV incidence over time in four sub-Saharan African cities, using simulation models. Methods: An individual-based stochastic model was fitted to demographic, behavioural and epidemiological data from cross-sectional population-based surveys in four African cities (Kisumu, Kenya; Ndola, Zambia; Yaoundé, Cameroon; and Cotonou, Benin) in 1997. To estimate the proportion of new HIV infections attributable to HSV-2 and other STIs over time, HIV incidence in the fitted model was compared with that in model scenarios in which the cofactor effect of the STIs on HIV susceptibility and infectivity were removed 5 , $10,15,20$ and 25 years into the simulated HIV epidemics.

Results: The proportion of incident HIV attributable to HSV-2 infection (the model estimated population attributable fraction $\left(\mathrm{PAF}_{M}\right)$ ) increased with maturity of the HIV epidemic. In the different cities, the $\mathrm{PAF}_{M}$ was $8-31 \% 5$ years into the epidemic, but rose to $35-48 \% 15$ years after the introduction of HIV. In contrast, the proportion of incident HIV attributable to chancroid decreased over time with strongest effects five years after HIV introduction, falling to no effect 15 years after. Sensitivity analyses showed that, in the model, recurrent HSV-2 ulcers had more of an impact on HIV incidence than did primary HSV-2 ulcers, and that the effect of HSV-2 on HIV infectivity may be more important for HIV spread than the effect on HIV susceptibility, assuming that HSV-2 has similar cofactor effects on HIV susceptibility and infectivity. The overall impact of other curable STIs on HIV spread (syphilis, gonorrhoea and chlamydia) remained relatively constant over time.

Conclusions: Although HSV-2 appears to have a limited impact on HIV incidence in the early stages of subSaharan African HIV epidemics when the epidemic is concentrated in core groups, it has an increasingly large impact as the epidemic progresses. In generalised HIV epidemics where control programmes for curable STIs are already in place, interventions against HSV-2 may have a key role in HIV prevention.
\end{abstract}

nfection with herpes simplex virus type 2 (HSV-2) is associated with a threefold increase in risk of HIV acquisition in both men and women in the general population. ${ }^{1}$ Given the high prevalence of HSV-2 in sub-Saharan Africa, ${ }^{2} \mathrm{HSV}-2$ may have an important role in the spread of HIV in these regions. Understanding the proportion of new HIV infections attributable to HSV-2, and how and why this proportion may change over time, will provide insight into current epidemic dynamics, and will help in designing and evaluating future HSV-2 interventions.

This paper uses model simulations of populations in four African cities as described by Orroth et al in this supplement. ${ }^{3}$ The individual-based stochastic model STDSIM was used to model the demography, sexual behaviour and STI/HIV epidemiology of four sub-Saharan Africa cities (Cotonou, Benin; Yaoundé, Cameroon; Ndola, Zambia; and Kisumu, Kenya), based on data from cross-sectional surveys in 1997 and other sources. ${ }^{4-15}$ Although many mathematical models have been used to simulate HIV, few models have been used to simultaneously simulate the transmission and interaction of HSV-2 and HIV. ${ }^{16-18}$ STDSIM allows for the simultaneous and interactive simulation of up to 16 different STIs.

In the present study, HIV, HSV-2, chancroid, syphilis, gonorrhoea and chlamydia were simulated in each of the four populations. Using STDSIM, we compared the proportion of HIV incidence attributable to HSV-2 over time with that due to chancroid and other curable STIs (syphilis, chlamydia and gonorrhoea) over the same time period in the four African cities. We also examined the sensitivity of model predictions to assumptions made regarding the association of HSV-2 with HIV, including assumptions relating to HSV-2 effects on HIV during periods of subclinical shedding of HSV-2. Finally, we looked at the relative importance to HIV spread of primary versus recurrent HSV-2 ulcers, and of HSV-2 effects on HIV infectivity compared with susceptibility.

\section{METHODS}

The mathematical model STDSIM was fitted to data collected from four sub-Saharan African cities and other data sources, as explained in detail by Orroth et al in this supplement. ${ }^{3}$ The model was primarily fitted to data from the Four Cities Study ${ }^{4}$ for the year 1997 and to available data on trends over time. ${ }^{5-15}$ The population attributable fractions of incident HIV due to HSV-2 and other STIs were then calculated for different time periods during the epidemic.

\section{Quantification of model parameters: HSV-2}

The model-assumed parameter values for HSV-2 are based on previous reviews and are shown in detail in the companion paper by Orroth et al in this supplement. ${ }^{3118}$ Infection with HSV-2 is followed by a primary ulcer lasting three weeks. ${ }^{17} 1920$

Abbreviations: HSV-2, herpes simplex virus 2; STD, sexually transmitted disease; STI, sexually transmitted infection 
All individuals are assumed to pass through this primary stage following infection with HSV-2, although in empirical studies some individuals fail to report a primary ulcer, perhaps due to lack of recognition rather than true absence. In this paper, the term ulcer refers to clinically recognisable herpetic lesions, whether or not they are recognised by the infected individual.

After the "primary stage", ulcers recur with decreasing frequency over time..$^{20-22}$ In the early latent stage, ulcers recur on average every 2.5 months for men and every three months for women, and in the latent stage, ulcers recur every six months for men and eight months for women. We assumed a sex difference in ulcer recurrence rates, ${ }^{21}$ although modelling this effect assumes the higher recurrence in men is not due to differences in symptom recognition. Ulcer recurrence rates were assumed to vary widely between individuals, ${ }^{23}$ so the duration of periods between ulcers and the duration of early latent and latent stages were sampled from an exponential distribution. ${ }^{17}$ Recurrent ulcers were assumed to last on average one week; a Weibull distribution ( shape parameter $=2$ ) was used to reflect the relative homogeneity of ulcer durations. ${ }^{17}$

After "early latent" and "latent" stages with recurrent ulcers, individuals enter the "late latent" stage, in which they are still HSV-2 positive but no longer experience recurrent ulcers. ${ }^{17}$ Stage duration is, on average, 3 weeks for primary, 2 years for early latent, 10 years for latent, with the rest of life in the late latent phase. Transmission probabilities for male-to-female transmission in all HSV-2 phases were assumed to be twice those of female-to-male transmission, as for HIV. ${ }^{24}{ }^{25}$ There are limited data on per contact transmission probabilities of HSV-2 due to the difficulties in measurement and problems of generalisability to the general population of results from wellcounselled but high-risk study populations. We assumed the primary HSV-2 stage to have the highest level of HSV-2 transmission (per contact male-to-female transmission probability 0.30 ), followed by periods of ulcer recurrence (male-tofemale 0.20). ${ }^{19}$ In addition, there is evidence that subclinical shedding of HSV-2 occurs during periods between ulcers. ${ }^{23} 2627$ HSV-2 transmission may occur during these periods of subclinical shedding ${ }^{24}$; therefore, a low (conservative) level of HSV-2 transmission was modelled continuously during the early latent (male-to-female 0.01) and latent (male-to-female 0.005 ) stages between ulcers to take this shedding effect into account. ${ }^{17} 1823^{27-32}$ Any effect of HSV-1 on HSV-2 was ignored, because HSV-1 infection is almost universal in sub-Saharan African populations. ${ }^{2}$

Per contact cofactor effects of HSV-2 on HIV susceptibility and infectivity were estimated using data from observational studies of Kenyan commercial sex workers and their clients. ${ }^{33} 34$ From this work, primary herpetic ulcers were estimated to be associated with a 25 -fold increase in the per contact transmission probability of HIV (as were chancroid ulcers). Recurrent HSV-2 ulcers were estimated to be associated with a 10-fold increase in the transmission probability of HIV, to match the reduced severity of these ulcers in comparison with the primary ulcer. ${ }^{17}$ HIV transmission probabilities per act have been found to increase with the presence of recent genital ulceration in an HIV-positive source partner. ${ }^{35}{ }^{36}$ Cofactor effect values were chosen to be at the lower end of the range of estimates from the Kenyan study (3-300) $)^{34}$ to account for possible bias.

The magnitudes of the stage-specific cofactor effects were assumed to be constant across all sites, but varied by stage of HSV-2 infection. For example, if a male was simultaneously in the primary stage of HSV-2 infection and the primary stage of HIV infection, then the per contact HIV transmission probability from that male to an uninfected female would be the product of the male-to-female transmission probability during primary HIV (0.028) and the cofactor effect for primary HSV-2 infection (25)-that is, 0.688. This overall per contact HIV transmission probability would quickly reduce either when the individual entered a HSV-2 stage with a lower cofactor for HIV transmission, or when the individual entered an HIV stage associated with lower infectivity. Equal cofactor effects were assumed for HIV infectivity and HIV susceptibility, increasing the risk of HIV transmission to an HIV-negative partner either when the HIV-positive source partner was also infected with HSV-2 (increased infectivity) or when the HIV-negative partner had an HSV-2 ulcer (increased HIV susceptibility). As there was a lack of definitive evidence that HSV-2 increases HIV infectivity more than HIV susceptibility, we were interested in comparing the population-level impacts of HSV-2 cofactor effects on infectivity and susceptibility acting through population mixing and sexual behaviour.

Conservatively, no increase in the risk of HIV susceptibility or infectivity was initially assumed for the periods of subclinical shedding of HSV-2 between ulcers. Co-infection with HIV in HSV-2 positive individuals has been shown to increase both the HSV-2 shedding rate and quantity (taken account of in the model, see below), ${ }^{35}$ 37-39 with several studies finding a significant correlation between genital HIV RNA and HSV-2 DNA in those HIV positive women who were shedding HSV-2, without finding the same correlation between HIV RNA and HSV-2 DNA in those dually infected overall. ${ }^{38} 4041$ New evidence (currently in preparation) from Burkina Faso and Peru suggests that HSV-2 therapy can reduce the frequency and quantity of HIV shedding as well as plasma HIV loads. We still await the definitive trial results on whether this decreased shedding is associated with reduced HIV transmission. The importance of this assumption of no increased risk of acquisition or transmission during subclinical shedding of HSV-2, as well as the importance of the values assumed for cofactors during ulcerative periods, were examined in a sensitivity analysis (see below).

HIV infection was also assumed to alter the natural history of HSV-2 infection. In line with evidence on increased HSV-2 shedding in HIV-positive individuals ${ }^{35}{ }^{37-41}$ and increased HSV ulcer recurrence rates in HIV-positive individuals ${ }^{39}{ }^{42-45}$ and with previous assumptions in STDSIM, ${ }^{17}$ we assumed a fourfold increase in HSV-2 ulcer duration and recurrence rate with the onset of symptomatic HIV.

\section{Quantification of model parameters: other STIs, demography and sexual behaviour}

Other model parameter values, for the demography, sexual behaviour and natural history of the other STIs and their interaction with HIV were as reported in our companion paper in this supplement. ${ }^{3}$ Briefly, chancroid infection was assumed to be associated with a cofactor effect of 25 on HIV susceptibility and infectivity. Gonorrhoea and chlamydia infection were assumed to have a cofactor effect of 3 on HIV, and primary stage syphilis was assumed to have a cofactor effect of 7.5 on HIV. ${ }^{3}$ It is important to note that in a sexual encounter when there is more than one STI present (one individual with two different STIs or two individuals with different STIs), only the highest of the relevant cofactor effects is assumed to act on the probability of HIV transmission in that sexual act. Cofactor effects were not assumed to be additive or multiplicative.

Simulated population composition and growth rate are determined in STDSIM by inputs relating to fertility, mortality and migration (see companion paper). In-migration is modelled by creating a simulated copy of an individual in the population in a specified age and relationship (risk) group. This simulated migration pattern allows us to adequately fit the population composition and observed patterns of behaviour. 


\section{Population attributable fraction calculation}

The modelled population attributable fractions $\left(\mathrm{PAF}_{\mathrm{M}}\right)$ of incident HIV attributable to HSV-2, chancroid and other curable STIs (syphilis, chlamydia and gonorrhoea) were calculated from the STDSIM model simulations in the following manner. The cofactor effects on HIV for a given STI were removed from the model for a two-year period-for example, during 1997 and 1998. HIV incidence in adults (15-49 years) over this two-year period was then compared with the HIV incidence in the default scenario in which the default cofactor effects were assumed. By removing cofactor effects for susceptibility, the $\mathrm{PAF}_{\mathrm{M}}$ can be calculated for effects of the STI on HIV acquisition. By simultaneously removing the cofactor effects for susceptibility and infectivity, overall $\mathrm{PAF}_{\mathrm{M}}$ can be calculated for effects of the STI on HIV acquisition and transmission. The following equation was used for the simulated $\mathrm{PAF}_{\mathrm{M}}$ calculations:

$$
P A F_{M}=\left(1-\frac{I R_{\text {nocofactor }}}{I R_{\text {defaultcofactor }}}\right) \times 100 \%
$$

where $I R_{\text {nocofactor }}$ is the incidence rate of HIV in model scenarios with the cofactor effect removed, and $I R_{\text {defaultcofactor }}$ is the incidence rate in model scenarios with the default cofactor effects of HSV-2 or other STIs on HIV. ${ }^{46}$

The $\mathrm{PAF}_{\mathrm{M}}$ for different time points in the epidemic was calculated by removing the STI cofactor effect on HIV over twoyear periods starting $5,10,15,20$ and 25 years after the introduction of HIV into each population (each in a separate set of simulations). Due to the earlier introduction of HIV assumed for Kisumu (1980) than the other cities (1984), the cofactors were removed during 1985/6, 1990/1, 1995/6, 2000/1 and 2005/6 in Kisumu and in 1989/90, 1994/5, 1999/2000, 2004/5 and 2009/10 in the other sites. The HIV incidence over the two-year period during the removal of the STI cofactor effects was averaged and was compared with HIV incidence over the same period in the default scenario for each site. This process was undertaken for the effects on HIV due to HSV-2, chancroid and other curable STIs combined (gonorrhoea, chlamydia and syphilis).

\section{Sensitivity analysis}

A sensitivity analysis was undertaken to assess the influence of the strength of the assumed HSV-2 cofactor effect on the proportion of new HIV cases attributable to HSV-2. Simulated $\mathrm{PAF}_{M}$ were calculated with the HSV-2 cofactor effects on HIV during primary HSV-2 and recurrent ulcerative periods at $50 \%$, $150 \%, 200 \%$ and $300 \%$ of their default values by removing the cofactor effects starting in 1998, the last year of the Four Cities Study, and comparing HIV incidence in these simulations with incidence in simulations without these new cofactors removed.

The effects of HSV-2 cofactors on HIV susceptibility and on HIV infectivity were compared to assess which had the greater impact on HIV spread. HIV incidence was calculated from simulations with the cofactors on susceptibility removed (with the cofactor effects on infectivity still in place), and then for simulations with cofactors on infectivity removed (with effects for susceptibility still in place). The $\mathrm{PAF}_{\mathrm{M}}$ was calculated by comparing these incidence levels to default simulations with the effects for infectivity and susceptibility in place. The sensitivity analysis also investigated the relative contribution of cofactor effects during primary HSV-2 with those assumed during ulcerative recurrent HSV-2 on HIV incidence. The $\mathrm{PAF}_{\mathrm{M}}$ was calculated for primary HSV-2 only (by selectively removing the cofactor effects during that period and comparing the incidence rates as above) and was then calculated for recurrent ulcerative periods of HSV-2 in a similar manner.

The effect of an additional inclusion of an HSV-2 cofactor effect on HIV during periods of subclinical HSV-2 shedding between ulcers was also explored. Various scenarios were explored including: cofactor effects between ulcers of 2 or 5; effects only during the early latent stage, or during both the early latent and latent stages and thus persisting many years into the course of HSV infection; and effects on susceptibility only, or on both susceptibility and infectivity.

\section{RESULTS}

The fit of the model simulations to data for demography, sexual behaviour and prevalence levels of STI is presented in our companion paper in this supplement. ${ }^{3}$ The fit of model simulated HSV-2 prevalence to data from the four cities can
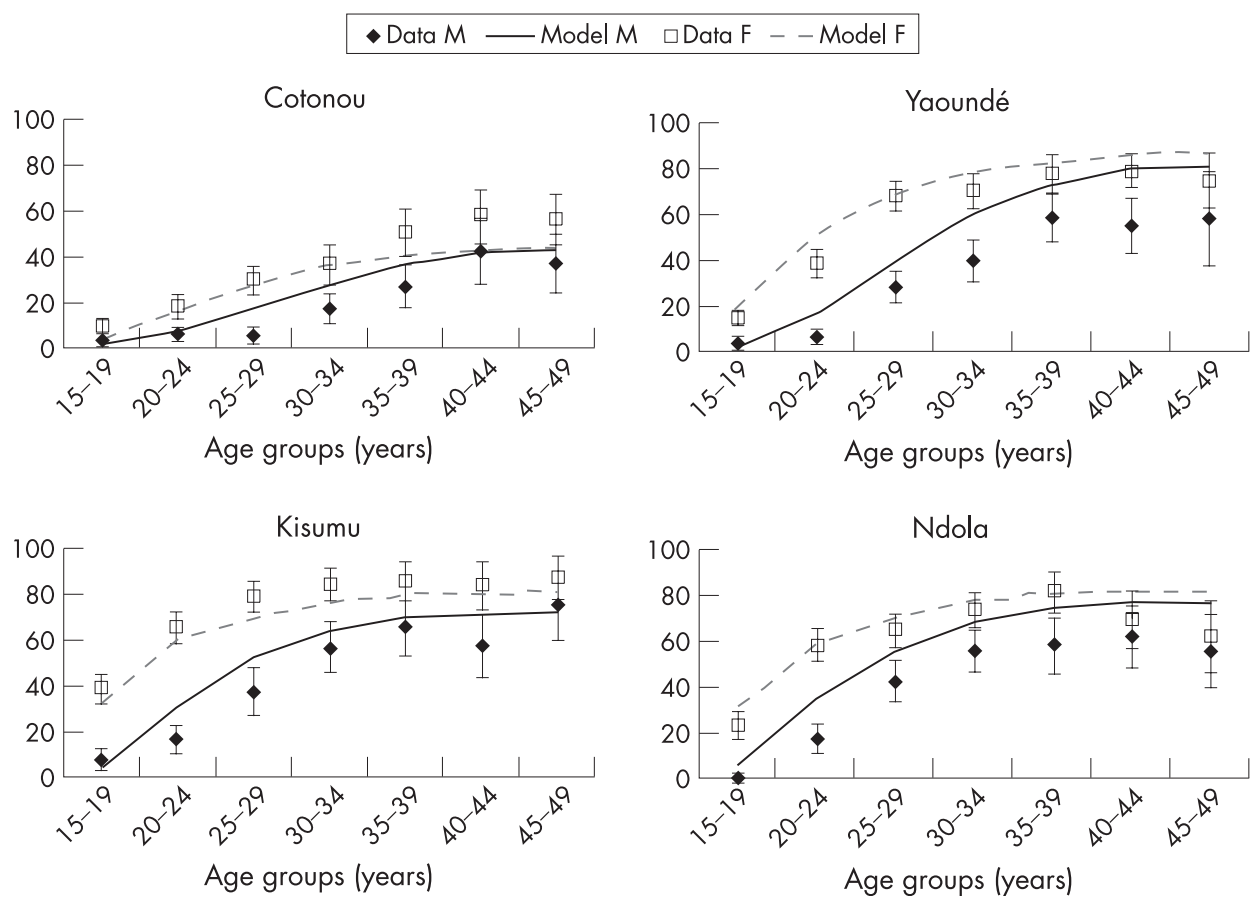

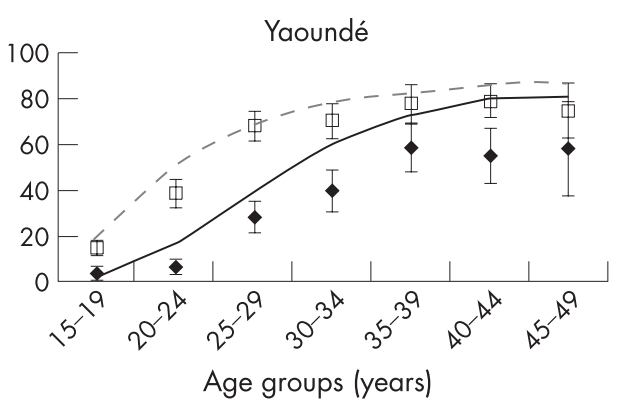

Age groups (years)
Figure 1 Observed (mean, 95\% Cl) and simulated prevalence of herpes simplex virus type 2 in the four cities in 1997. M, male; $F$, female. 

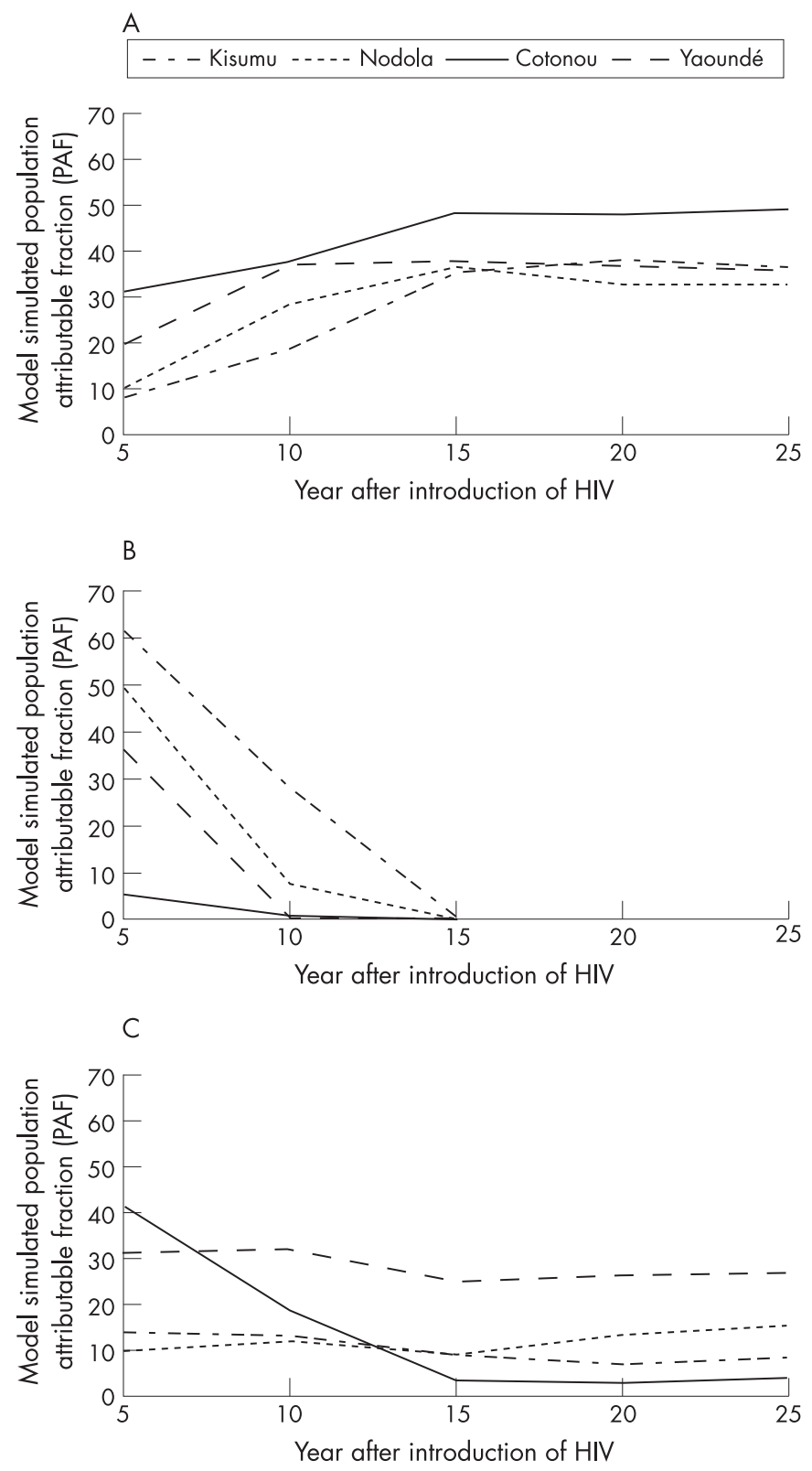

Figure 2 Simulated proportion of adult (15-49 years) new HIV infections due to (A) herpes simplex virus type 2 (B) chancroid (C) syphilis, chlamydia and gonorrhoea, by year after the introduction of HIV.

be seen in figure 1. Prevalence of HSV-2 in younger age groups was fitted preferentially, because younger individuals account for a higher proportion of new HIV and HSV-2 infections. As a result, HSV-2 prevalence in older adults was slightly overestimated in Yaoundé and Ndola, and underestimated in Cotonou. In all the sites, prevalence of HSV-2 in younger males was allowed to be overestimated in favour of fitting the prevalence of HSV-2 in younger females, because higher-risk males may not have been completely captured in the original surveys. ${ }^{47}$ The fit of HSV-2 prevalence reflects the general age trends in HSV-2 prevalence and the important differences between the four sites, such as the difference in HSV-2 prevalence in females aged 15-19 years in Cotonou (9\%) and Kisumu (39\%). ${ }^{48}$ Due to the sensitivity of simulated HIV prevalence and short-duration STI prevalence to the alteration of sexual behaviour parameters, these parameters could not be further altered to improve the fit. Natural history parameters were held constant across all four sites.
Figure 2 shows the proportion of new HIV infections attributable to other STIs over time $\left(\mathrm{PAF}_{M}\right)$. The results were similar for males and females when examined separately by sex; the $\mathrm{PAF}_{M}$ shown are for males and females aged 15-49 years combined. Figure 2A shows the proportion of HIV incidence due to HSV-2, which increased with the maturity of the epidemic in all four sites. The $\mathrm{PAF}_{\mathrm{M}}$ across the four cities rose from $8.2-30.9 \%$ five years after the introduction of HIV to $35.4-48.2 \% 15$ years after, as the HIV epidemic spread from core groups to the general population. The proportion of new HIV infections due to HSV-2 was highest in Cotonou, especially earlier on in the epidemic. This effect is due to the relative lack of other (ulcerative) STIs in Cotonou (see fig 3), so that HSV-2 accounted for proportionately more of the HIV transmission in that site. Although the $\mathrm{PAF}_{M}$ in Yaoundé increased dramatically between five years and 10 years after the introduction of HIV, it levelled off at around $37 \%$ after this 10 -year mark. This pattern matches the concurrent decrease observed in other STIs besides HSV-2 in Yaoundé, which were highly prevalent five years after the introduction of HIV (corresponding to 1989 in fig 3) but had declined by 10 years after HIV introduction (1994). This was due simulated condom use and implementation of syndromic treatment in the early 1990s in the Yaoundé scenario. In all four sites, whereas the $\mathrm{PAF}_{M}$ of incident HIV due to HSV-2 increased over time, the HSV-2 prevalence remained constant.

The rapid increase in new HIV infections attributable to HSV-2 over time contrasted markedly with the rapid decrease in HIV infections due to chancroid over time, as shown in figure $2 \mathrm{~B}$. Fifteen years after the introduction of HIV, all the chancroid $\mathrm{PAF}_{M}$ for HIV infection had fallen to zero due to the simulated decline in chancroid prevalence over time because of the simulated implementation of condom use and syndromic treatment ${ }^{3}$ starting in the early 1990s (fig 3). Overall, the drop in $\mathrm{PAF}_{\mathrm{M}}$ of HIV due to chancroid and rise in $\mathrm{PAF}_{\mathrm{M}}$ of HIV due to HSV-2 occurred while the HIV incidence continued to rise (the effective reproduction number remaining $>1$ ). As can be expected from the explanations above, the $\mathrm{PAF}_{\mathrm{M}}$ of HIV due to chancroid were the inverse of those for HSV-2 in terms of sitespecific value, with the $\mathrm{PAF}_{M}$ in Cotonou for HIV due to chancroid much lower than in the other sites.

The $\mathrm{PAF}_{\mathrm{M}}$ of HIV attributable to other curable STIs (syphilis, chlamydia and gonorrhoea) can be seen in figure 2C. In three sites, the proportion of HIV incidence due to these STIs remained relatively constant throughout the HIV epidemic. In Cotonou, in contrast, this proportion decreased rapidly from a little over $40 \%$ five years into the HIV epidemic to less than $5 \%$ 15 years into the epidemic.

The simulated prevalence of curable STIs over time is presented in figure 3 . There are no consistent empirical timetrend data available from the four cities with which to compare these prevalence levels, but the figure is included to provide insight into the simulated $\mathrm{PAF}_{\mathrm{M}}$ over time seen in figure 2 . The irregularity in the prevalence levels of curable STIs is due to simulated improvements in syndromic management over time (introduced in the model in 1992 in Kisumu, Ndola and Yaoundé, and in 1995 in Cotonou) and the use of condoms (introduced at a low level in 1990, increased in 1993 and 1995 in commercial sex workers, and increased in 1995 for general population casual relationships). An initial dip can be seen in the curable STI prevalences in 1990, corresponding to the introduction of low-level condom use, followed by further decreases due to the introduction of improved syndromic management and higher condom use. By 1995, simulated chancroid had all but disappeared in the four sites.

Overall, the HSV-2 $\mathrm{PAF}_{\mathrm{M}}$ were relatively insensitive to changes in assumed cofactor strength. Figure 4 shows the 
$-N G---C T---T P-H D$

Cotonou

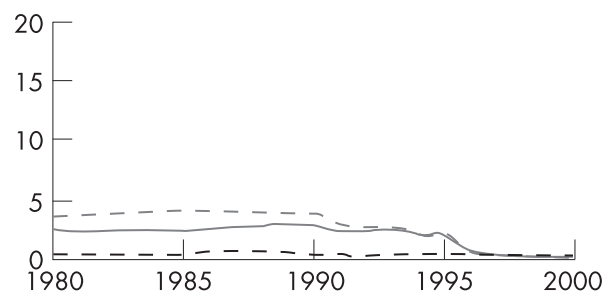

Kisumu

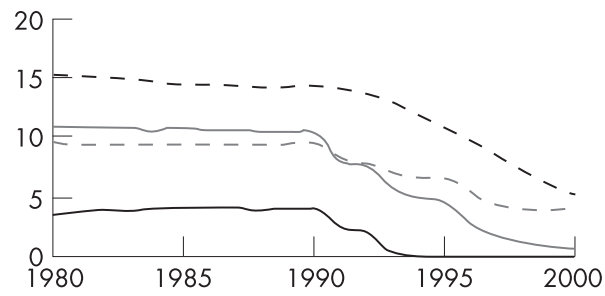

Yaoundé
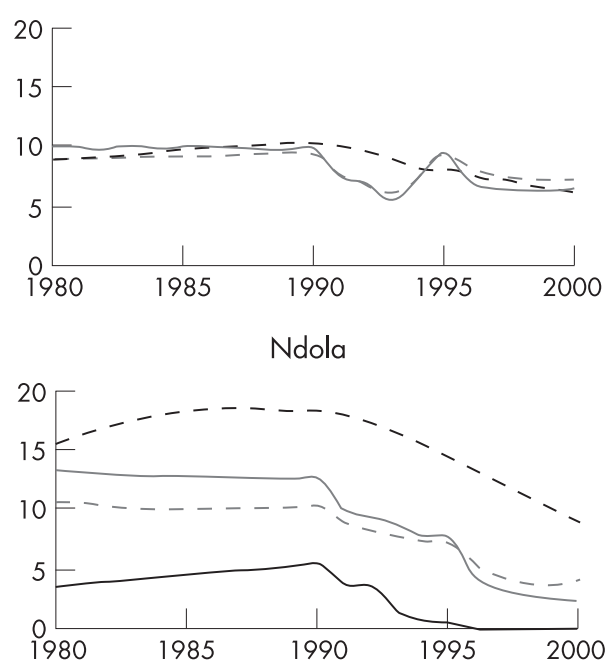

Figure 3 Simulated prevalence of curable sexually transmitted infections (STIs) over time, reflecting changes in STI treatment and in condom use: chancroid (HD), gonorrhoea (NG), syphilis (TP) and chlamydia (CT) from 1980 to 2000.
$\mathrm{PAF}_{\mathrm{M}}$ as a function of assumed cofactor strength in 1998. Reducing all of the HSV-2 cofactor effects on HIV by half only decreased the proportion of new HIV infections from the default value of $36.1-47.9 \%$ to $21.3-30.5 \%$, suggesting that HSV-2 would still have a large role in HIV transmission even if our assumed default cofactor values were too large. As the magnitude of HSV-2 cofactor effects on HIV was increased substantially, to $200 \%$ and $300 \%$ of default values, the $\mathrm{PAF}_{\mathrm{M}}$ began to slowly level off, suggesting that, as could be expected, the proportion of new HIV infections attributable to HSV-2 will reach its maximum well below 100\%.

Further sensitivity analyses of the HSV-2 $\mathrm{PAF}_{M}$ are presented by sex in table 1 . The $\mathrm{PAF}_{\mathrm{M}}$ was similar for males and females. An analysis of the contribution of primary HSV-2 compared with recurrent HSV-2 ulcers to new HIV infections can be seen in this table. The proportion of new HIV infections due to recurrent HSV-2, ranging from $26.4 \%$ to $36.0 \%$, was much higher than the proportion due to primary HSV-2, ranging from $6.3 \%$ to $11.2 \%$. This effect was observed because primary HSV-2, while assumed to have a much higher cofactor on HIV susceptibility and transmission, is also much shorter in duration than the combined total of all recurrent ulcerative episodes.

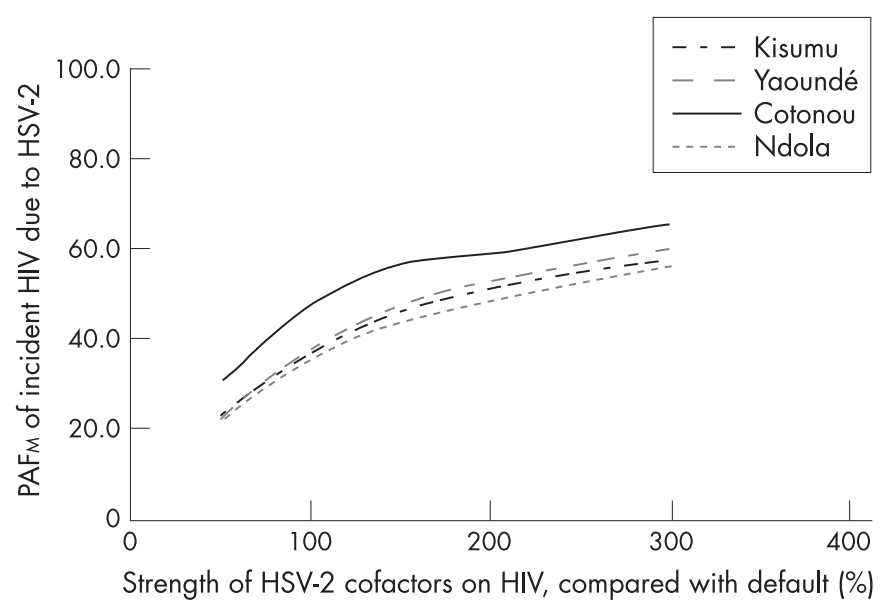

Figure 4 Sensitivity analysis: the proportion of incident HIV due to herpes simplex virus type 2 (HSV-2) in 1998, by magnitude of HSV-2 cofactor for $\mathrm{HIV}$ transmission and acquisition. $\mathrm{PAF}_{M}$, population attributable fraction.
The contribution to new HIV infections of the effect of HSV-2 on HIV susceptibility as compared to HIV infectivity can also be seen in table 1. Assuming cofactor effects of equal strength, the cofactor effects on HIV transmissibility/infectivity contributed substantially more than those on susceptibility to the overall effect that HSV-2 has on the spread of HIV. In Cotonou, for example, the overall $\mathrm{PAF}_{\mathrm{M}}$ of incident HIV due to HSV-2 was $47.9 \%$ in 1998 , with a $\mathrm{PAF}_{\mathrm{M}}$ of $9.7 \%$ due to the cofactors on HIV susceptibility and $31.8 \%$ due to the cofactors on HIV infectivity.

Finally, the sensitivity of the $\mathrm{PAF}_{\mathrm{M}}$ to the introduction of an additional cofactor effect of HSV-2 on HIV due to HSV subclinical shedding can also be seen in table 1. An assumed cofactor effect of 2 during subclinical shedding results in a negligible increase in the $\mathrm{PAF}_{\mathrm{M}}$ when the cofactor is assumed only to act during early latency (not shown). A slightly stronger effect is seen if the cofactor is assumed for both early latency and latency. As expected, an even stronger assumed cofactor effect during periods of subclinical shedding increases the $\mathrm{PAF}_{\mathrm{M}}$ of HIV due to HSV-2, but a large increase is seen only if cofactor effects of 5 or greater are assumed for both HIV susceptibility and infectivity.

\section{DISCUSSION}

The present study showed HSV-2 to have an increasingly important role in HIV spread in these four urban African populations. We estimate that more than a third of new HIV cases were attributable to HSV-2 infection $\left(\mathrm{PAF}_{\mathrm{M}}\right.$ of $\left.>30 \%\right)$ at the time of the Four Cities Study. This was larger than the $\mathrm{PAF}_{M}$ for syphilis, gonorrhoea and chlamydia taken together, and also for chancroid. The $\mathrm{PAF}_{\mathrm{M}}$ for HSV-2 was low at the start of the HIV epidemic in all four cities but increased rapidly over time as the epidemic became more generalised and as the prevalence of other STIs with high cofactor effects on HIV acquisition and transmission decreased (with STI treatment and preventative measures in place). In Yaoundé, for example, the early decrease in prevalence of other ulcerative STIs in response to simulated interventions was matched by an early increase and then stabilisation in the $\mathrm{PAF}_{\mathrm{M}}$ for HSV-2. In contrast, the simulations showed that chancroid had an important role in establishing the HIV epidemics in three of the four cities, but its effect decreased rapidly over time with simulated implementation of condom use and syndromic treatment, the simulated PAF for HIV incidence falling to zero by 15 years into the HIV epidemic. Chancroid has a low basic 
Table 1 Sensitivity analysis of population attributable fraction in 1998 to assumptions regarding the herpes simplex virus type 2 (HSV-2) cofactor on HIV: (a) primary versus recurrent ulcers; (b) susceptibility versus infectivity; (c) absence versus presence of cofactor on HIV during HSV-2 subclinical periods

\begin{tabular}{|c|c|c|c|c|c|c|c|c|c|}
\hline & \multicolumn{9}{|c|}{ Proportion of new HIV infections in the population attributable to HSV-2 $\left(\mathrm{PAF}_{\mathrm{M}}\right)$} \\
\hline & \multirow{3}{*}{$\begin{array}{l}\text { Default PAF } \\
\text { due to HSV-2 } \\
\text { (\%) }\end{array}$} & \multirow{3}{*}{$\begin{array}{l}\mathrm{PAF}_{M} \text { due to } \\
\text { primary HSV-2 } \\
\text { only }(\%)\end{array}$} & \multirow{3}{*}{$\begin{array}{l}\mathrm{PAF}_{M} \text { due to } \\
\text { recurrent HSV-2 } \\
\text { only (\%) }\end{array}$} & \multirow{3}{*}{$\begin{array}{l}\text { PAFM due to HSV-2 } \\
\text { cofactors on HIV } \\
\text { susceptibility only } \\
\text { (\%) }\end{array}$} & \multirow{3}{*}{$\begin{array}{l}\text { PAFM due to HSV-2 } \\
\text { cofactors on HIV } \\
\text { infectivity only (\%) }\end{array}$} & \multicolumn{4}{|c|}{$\begin{array}{l}\text { PAF }_{M} \text { due to default HSV-2 cofactors on HIV with the addition of the } \\
\text { following cofactors assumed during periods between ulcerative episodes in } \\
\text { early latent and latent stages of HSV-2 }\end{array}$} \\
\hline & & & & & & \multicolumn{2}{|c|}{ Effect on HIV susceptibility only } & \multicolumn{2}{|c|}{ Effect on HIV susceptibility and infectivity } \\
\hline & & & & & & Cofactor of 2 & Cofactor of 5 & Cofact & 2 Cofactor of 5 \\
\hline \multicolumn{10}{|l|}{ Kisumu } \\
\hline M 15-49 & 37.2 & 7.2 & 27.0 & 8.7 & 25.9 & 37.5 & 46.8 & 39.7 & 53.9 \\
\hline F 15-49 & 37.7 & 5.8 & 26.8 & 9.0 & 23.8 & 42.4 & 49.8 & 44.4 & 54.3 \\
\hline$M$ and $F$ 15-49 & 37.5 & 6.5 & 26.9 & 8.8 & 24.8 & 40.1 & 48.4 & 42.2 & 54.1 \\
\hline \multicolumn{10}{|l|}{ Ndola } \\
\hline M 15-49 & 35.1 & 7.3 & 26.3 & 9.1 & 24.4 & 35.6 & 43.6 & 35.4 & 49.8 \\
\hline F $15-49$ & 37.0 & 6.9 & 26.5 & 8.8 & 22.5 & 39.8 & 47.1 & 42.2 & 52.2 \\
\hline$M$ and F 15-49 & 36.1 & 7.1 & 26.4 & 9.0 & 23.4 & 37.9 & 45.6 & 39.1 & 51.1 \\
\hline \multicolumn{10}{|l|}{ Cotonou } \\
\hline M 15-49 & 52.0 & 12.0 & 41.8 & 9.6 & 40.1 & 56.1 & 62.6 & 58.9 & 69.7 \\
\hline F $15-49$ & 44.9 & 10.6 & 31.7 & 9.8 & 25.9 & 46.2 & 53.9 & 49.3 & 57.1 \\
\hline$M$ and F 15-49 & 47.9 & 11.2 & 36.0 & 9.7 & 31.8 & 50.3 & 57.6 & 53.4 & 62.7 \\
\hline \multicolumn{10}{|l|}{ Yaoundé } \\
\hline M 15-49 & 39.7 & 6.7 & 29.2 & 9.0 & 27.7 & 43.8 & 53.0 & 46.1 & 61.0 \\
\hline F $15-49$ & 36.0 & 6.0 & 26.8 & 8.6 & 22.7 & 40.1 & 50.9 & 41.9 & 56.0 \\
\hline$M$ and $F$ 15-49 & 37.5 & 6.3 & 27.8 & 8.8 & 24.8 & 41.7 & 51.8 & 43.7 & 58.1 \\
\hline
\end{tabular}

reproduction number and tends to cluster in groups at high risk, explaining its strong effect on HIV transmission during the growth phase of an HIV epidemic. As HIV spreads beyond highrisk groups into the general population, chancroid plays a less important part in transmission. It is also highly symptomatic and therefore amenable to improvements in STI treatment services, disappearing rapidly once these services are in place.

The combined $\mathrm{PAF}_{M}$ for syphilis, chlamydia and gonorrhoea declined over time in Cotonou. In this site, high levels of STI treatment were introduced for commercial sex workers in model simulations in line with empirical data. ${ }^{3950}$ As Cotonou is still a concentrated epidemic, STI treatment in this particular group had a large effect on prevalence levels of curable STIs. The $\mathrm{PAF}_{M}$ due to syphilis, chlamydia and gonorrhoea was relatively constant over time in the other sites, falling only slightly after the assumed introduction of more limited STI treatment services in these populations. At the current stage of the HIV epidemics, and given the current level of condom use and provision of STI treatment services, further strengthening of treatment services for curable STIs may be expected to produce little additional gain, except possibly in Yaoundé where the $\mathrm{PAF}_{\mathrm{M}}$ approached $30 \%$. However, withdrawing these

\section{Key messages}

- The impact of HSV-2 and other STIs on the spread of the simulated HIV epidemic in four sub-Saharan African cities has changed over time.

- The proportion of incident HIV attributable to HSV-2 increased over time with the maturity of the epidemic, whereas the proportion of incident HIV attributable to chancroid and other curable STIs diminished over time.

- In generalised HIV epidemics with control programmes for curable STls already in place, interventions against HSV-2 may have a key role in HIV prevention. services would most likely result in increased prevalence of curable STIs and increased HIV transmission.

The model-simulated $\mathrm{PAF}_{M}$ for HIV attributable to HSV-2 were similar to those calculated from relative risks. A recent meta-analysis estimated that $38-60 \%$ of new HIV infections in sub-Saharan African women and 8-49\% of new HIV infections in men could be due to HSV- $2,{ }^{1}$ depending on HSV-2 prevalence levels that ranged from $29 \%$ to $71 \%$ in women and $5 \%$ to $53 \%$ in men. ${ }^{2}$ However, these empirical estimates would not include those incident HIV infections due to increased transmissibility/ infectivity of HIV, as the simulations do, because cohort studies measure incidence among HIV-negative individuals. Our major findings from the model were the robust assumptions about the strength of the interaction between HIV and HSV-2. Although the absolute value of the $\mathrm{PAF}_{M}$ was somewhat sensitive to the cofactor values assumed, even reducing all cofactor values to half of their originally assumed value still resulted in a high proportion of new HIV cases due to HSV-2 at the time of the Four Cities Study. Increasing HSV-2 cofactor effects on HIV resulted in higher $\mathrm{PAF}_{\mathrm{M}}$, although the proportion of new HIV cases attributable to HSV-2 became saturated at around $60 \%$. Model simulations showed that recurrent HSV-2 ulcers contributed more to HIV incidence than did primary HSV-2 ulcers, probably because of the longer duration over which the recurrent ulcerative HSV-2 cofactors acted on HIV, despite recurrent ulcers being less severe than primary ulcers.

HSV-2 cofactor effects on HIV, assumed to be at the same per contact level for susceptibility and infectivity, appear to increase HIV incidence at the population level more through their effect on HIV infectivity than on their effect on HIV susceptibility. This effect may have been observed because increased susceptibility to HIV only increases that particular individual's probability of contracting HIV (passing it on to another individual is another step), whereas increased infectivity of HIV in an individual could more immediately influence multiple transmissions if that individual had multiple partners. In addition, HIV-infected individuals are also more likely to be coinfected with HSV-2 due to the strong association between HIV and HSV-2 ${ }^{151}$; therefore, in discordant partnerships, more of the HIV-positive partners will be HSV-2 positive. This finding 
suggests that empirically calculated PAF, relying on relative risks of HIV acquisition only, may underestimate the effect of HSV-2 on HIV incidence. ${ }^{46}$

Introducing hypothetical, low level cofactor effects during subclinical shedding of HSV-2 had little impact on HIV spread. A cofactor almost equivalent to that applied during recurrent ulcers would have to be assumed before making a large impact on HIV spread. This effect is understandable considering the nonadditive way in which the STDSIM model uses cofactors to increase HIV susceptibility and transmissibility, with the strongest cofactor in a given sexual encounter taken as the only cofactor. If only a low cofactor effect is assumed during subclinical shedding, only in partnerships with neither partner having additional active STIs would subclinical shedding of HSV-2 begin to increase the likelihood for HIV transmission, although this may already be the case in more generalised epidemics. The current STDSIM model does not allow for more than one cofactor to have an effect during a given sexual encounter. Further work will be done on the implications of this assumption, and alternative methods of combination of cofactor effects need to be explored.

Another effect of note was the consistently high proportion of HIV cases due to HSV-2 in Cotonou compared with the other sites. Cotonou had the lowest levels of other ulcerative STIs, even lower than in Yaoundé, due to STI treatment in commercial sex workers and to comparatively less risky sexual behaviour in the general population. In addition, examining the time trend of other STIs over time, the rise in the proportion of HIV due to HSV-2 was concurrent with the decrease in other STIs in that site. In other sites, the cofactor effects of other STIs competed with those of HSV-2, because the model only took into account the highest cofactor effect for a given sexual encounter. The simulated $\mathrm{PAF}_{M}$ should be interpreted with care, because it calculates the total effect of HSV-2 on HIV acquisition and transmission. Although it is not directly comparable with PAF calculated from empirical relative risks of HIV acquisition, it may, however, give us a better idea of the "true" PAF of HIV incidence due to effects on both HIV susceptibility and transmissibility. ${ }^{46}$ The fit of the HIV epidemic and HSV-2 epidemic was based on the best available data from the four cities, and, where unavailable, from outside sources. Further data on STI prevalence trends over time in the four cities would have been informative. Importantly, the prevalence of chancroid in the four cities was unknown historically and at the time of the Four Cities Study.

The model used in this study was primarily parameterised using cross-sectional data, the limitations of which are well known. Cross-sectional data provide little information on epidemiological or behavioural trends over time. Incorrect assumptions regarding the historic trends may alter our estimates of the proportion of new HIV cases due to STIs over time. However, the model did successfully replicate the observed time trends in HIV for the four cities. ${ }^{3}$

The findings of this paper have potential implications for ongoing and future trials of HSV-2 interventions. That the proportion of incident HIV due to HSV-2 may change over time along with the changing prevalence of other STIs in the population suggests that the timing of an intervention in a population, and the prevalence of other cofactors for HIV transmission present in that population at that given time-point, may be very important. Our simulations suggest that HSV-2 is now responsible for a large proportion of new HIV infections in these African settings, highlighting the potential impact of herpes control for HIV prevention. Empirical trials of such interventions are now underway, and their results are eagerly awaited.

\section{ACKNOWLEDGEMENTS}

The authors would like to thank the Wellcome Trust (Grant 069509/Z/ 02/Z) and the Marshall Scholarship Commission for their financial support. We also extend our gratitude to the original participants of the Four Cities Study.

\section{Authors' affiliations}

Esther E Freeman, Kate Orroth, Richard White, Judith R Glynn, Richard

Hayes, London School of Hygiene and Tropical Medicine, London, UK

Roel Bakker, Dik Habbema, Erasmus MC, University Medical Center

Rotterdam, Rotterdam, the Netherlands

Marie-Claude Boily, Imperial College, London, UK

Anne Buvé, Institute of Tropical Medicine, Antwerp, Belgium

Competing interests: None.

\section{REFERENCES}

1 Freeman EE, Weiss HA, Glynn JR, et al. Herpes simplex virus 2 infection increases HIV acquisition in men and women: systematic review and metaanalysis of longitudinal studies. AIDS 2006;20:73-83.

2 Smith JS, Robinson NJ. Age-specific prevalence of infection with herpes simplex virus types 2 and 1: a global review. J Infect Dis 2002;186(Suppl 1):S3-28.

3 Orroth KK, Freeman EE, Bakker R, et al. Understanding the differences between contrasting HIV epidemics in east and west Africa: results from a simulation model of the Four Cities Study. Sex Transm Infect 2007;83(Suppl 1):i5-i16.

4 Buve A, Carael M, Hayes RJ, et al. Multicentre study on factors determining differences in rate of spread of HIV in sub-Saharan Africa: methods and prevalence of HIV infection. AIDS 2001;15(Suppl 4):S5-14.

5 Anon. Zambia Demographic and Health Surveys, 1996. Zambia and Calverton MD: Central Statistical Office, Ministry of Health, and Macro International, 1997

6 Anon. 1998 Zambia sexual behaviour survey with selected findings from the quality of STD services assessment. Zambia and Chapel Hill, NC: Central Statistical Office, Ministry of Health; Project Concern International, MEASURE Evaluation, University of North Carolina at Chapel Hill, 1999.

7 Anon. Kenya Demographic and Health Survey 1998. Kenya and Calverton, MD National Council for Population and Development (NCPD), Central Bureau of Statistics (CBS), Office of the Vice President and Ministry of Planning and National Development and Macro International, 1999.

8 Anon: Zambia Demographic and Health Survey 2001-2002. Zambia and Calverton, MD: Central Statistical Office, Central Board of Health, and ORC, 2003.

9 Anon. Enquête Démographique et de Santé au Bénin 2001 [Demographic and Health Survey final report]. Calverton, MD: Institut National de la Statistique et de l'Analyse Économique et ORC, 2002.

10 Fotso M, Ndonou R, Libite PR, et al. Enquête Démographique et de Santé, Cameroun 1998 [Demographic and Health Survey Final Report]. Calverton, MD: Bureau Central des Recensements et des Études de Population et Macro International, 1999.

11 Nicaise K, Mboup G, Tossou J, et al. Enquete Demographique et de Sante, Republique de Benin 1996. Calverton, MD: Institut National de la Statistique et de l'Analyse Economique et Macro International, 1997.

12 Balepa M, Fotso M, Barrere B. Enquete Demographique et de Sante Cameroun 1991. Yaoundé, Cameroun: Direction Nationale due Deuxieme Recensement General de la Population et de l'Habitat, et Macro Inc, 1992.

13 Anon. Kenya Demographic and Health Survey 1989. Nairobi, Kenya: National Council for Population Development, Ministry of Home Affairs, National Heritage Institute for Resource Development, Macro Systems, 1999

14 Kenya Demographic and Health Survey 1993. Nairobi, Kenya and Calverton, MD: National Council for Population and Development, Central Bureau of Statistics, Office of the Vice President and Ministry of Planning and National Development, and Macro International, 1994.

15 Gaisie K, Cross A, Nsemukila G. Zambia Demographic and Health Survey 1992. Lusaka, Zambia: University of Zambia, Central Statistics Office, and Macro International, 1993.

16 Blower S, Ma L. Calculating the contribution of herpes simplex virus type 2 epidemics to increasing HIV incidence: treatment implications. Clin Infect Dis 2004;39(Suppl 5):S240-7.

17 Korenromp EL, Bakker R, De Vlas SJ, et al. Can behavior change explain increases in the proportion of genital ulcers attributable to herpes in sub-Saharan Africa? A simulation modeling study. Sex Transm Dis 2002;29:228-38.

18 Korenromp EL, Bakker R, Gray R, et al. The effect of HIV, behavioural change, and STD syndromic management on STD epidemiology in sub-Saharan Africa: simulations of Uganda. Sex Transm Infect 2002;78(Suppl 1):i55-63.

19 Corey L, Adams HG, Brown ZA, et al. Genital herpes simplex virus infections: clinical manifestations, course, and complications. Ann Intern Med 1983;98:958-72.

20 Koelle DM, Benedetti J, Langenberg A, et al. Asymptomatic reactivation of herpes simplex virus in women after the first episode of genital herpes. Ann Intern Med 1992;116:433-7.

21 Benedetti J, Corey L, Ashley R. Recurrence rates in genital herpes after symptomatic first-episode infection. Ann Intern Med 1994;121:847-54.

22 Benedetti JK, Zeh J, Corey L. Clinical reactivation of genital herpes simplex virus infection decreases in frequency over time. Ann Intern Med 1999;131:14-20.

23 Wald A, Zeh J, Selke S, et al. Virologic characteristics of subclinical and symptomatic genital herpes infections. N Engl J Med 1995;333:770-5.

24 Mertz GJ, Benedetti J, Ashley R, et al. Risk factors for the sexual transmission of genital herpes. Ann Intern Med 1992;116:197-202. 
25 Mertz GJ, Ashley R, Burke RL, et al. Double-blind, placebo-controlled trial of a herpes simplex virus type 2 glycoprotein vaccine in persons at high risk for genital herpes infection. J Infect Dis 1990;161:653-60.

26 Krone MR, Wald A, Tabet SR, et al. Herpes simplex virus type 2 shedding in human immunodeficiency virus-negative men who have sex with men: frequency, patterns, and risk factors. Clin Infect Dis 2000;30:261-7.

27 Wald A, Zeh J, Selke S, et al. Reactivation of genital herpes simplex virus type 2 infection in asymptomatic seropositive persons. N Engl J Med 2000;342:844-50

28 Adam E, Kaufman RH, Mirkovic RR, et al. Persistence of virus shedding in asymptomatic women after recovery from herpes genitalis. Obstet Gynecol 1979:54:171-3.

29 McCaughtry ML, Fleagle GS, Docherty JJ. Inapparent genital herpes simplex virus infection in college women. J Med Virol 1982;10:283-90.

30 Corey L. The current trend in genital herpes. Progress in prevention. Sex Transm Dis 1994;21(2 Suppl):S38-44.

31 Corey L, Wald A, Patel R, et al. Once-daily valacyclovir to reduce the risk of transmission of genital herpes. N Engl J Med 2004;350:11-20.

32 Wald A, Corey L, Cone R, et al. Frequent genital herpes simplex virus 2 shedding in immunocompetent women. Effect of acyclovir treatment. J Clin Invest 1997;99:1092-7

33 Hayes RJ, Schulz KF, Plummer FA. The cofactor effect of genital ulcers on the perexposure risk of HIV transmission in sub-Saharan Africa. J Trop Med Hyg 1995;98:1-8.

34 Korenromp EL, de Vlass SJ, Nagelkerke NJ, et al. Estimating the magnitude of STD cofactor effects on HIV transmission: How well can it be done? Sex Transm Dis 2001;28:613-21.

35 Corey L, Wald A, Celum CL, et al. The effects of herpes simplex virus-2 on HIV-1 acquisition and transmission: a review of two overlapping epidemics. $J$ Acquir Immune Defic Syndr 2004;35:435-45.

36 Grosskurth H, Gray R, Hayes R, et al. Control of sexually transmitted diseases for HIV-1 prevention: understanding the implications of the Mwanza and Rakai trials. Lancet 2000;355:1981-7.

37 Mbopi Keou FX, Gresenguet G, Mayaud P, et al. Genital herpes simplex virus type 2 shedding is increased in HIV-infected women in Africa. AIDS 1999;13:536-7.

38 Mbopi-Keou FX, Gresenguet G, Mayaud P, et al. Interactions between herpes simplex virus type 2 and human immunodeficiency virus type 1 infection in African women: opportunities for intervention. J Infect Dis 2000;182:1090-6.
39 Schacker T, Zeh J, Hu HL, et al. Frequency of symptomatic and asymptomatic herpes simplex virus type 2 reactivations among human immunodeficiency virusinfected men. J Infect Dis 1998;178:1616-22.

40 Mbopi-Keou FX, Legoff J, Gresenguet G, et al. Genital shedding of herpes simplex virus-2 DNA and HIV-1 RNA and proviral DNA in HIV-1- and herpes simplex virus-2-coinfected African women. J Acquir Immune Defic Syndr 2003;33:121-4.

41 McClelland RS, Wang CC, Overbaugh J, et al. Association between cervical shedding of herpes simplex virus and HIV-1. AIDS 2002;16:2425-30.

42 Kaul R, Kimani J, Nagelkerke NJ, et al. Risk factors for genital ulcerations in Kenyan sex workers. The role of human immunodeficiency virus type 1 infection. Sex Transm Dis 1997:24:387-92.

43 Glesby MJ, Hoover DR, Tan T, et al. Herpes zoster in women with and at risk for HIV: data from the women's interagency HIV study. J Acquir Immune Defic Syndr 2004;37:1604-9.

44 Posavad CM, Wald A, Kuntz S, et al. Frequent reactivation of herpes simplex virus among $\mathrm{HIV}$-1-infected patients treated with highly active antiretroviral therapy. J Infect Dis 2004;190:693-6.

45 Hitti J, Watts DH, Burchett SK, et al. Herpes simplex virus seropositivity and reactivation at delivery among pregnant women infected with human immunodeficiency virus-1. Am J Obstet Gynecol 1997;177:450-4.

46 Orroth K, White RG, Korenromp EL, et al. Empirical observations underestimate the proportion of HIV infections attributable to sexually transmitted diseases in the Mwanza and Rakai STD treatment trials: simulation results. Sex Transm Dis 2006;33:536-44.

47 Buve A, Lagarde E, Carael M, et al. Interpreting sexual behaviour data: validity issues in the multicentre study on factors determining the differential spread of HIV in four African cities. AIDS 2001;15(Suppl 4):S117-26.

48 Weiss HA, Buve A, Robinson NJ, et al. The epidemiology of HSV-2 infection and its association with $\mathrm{HIV}$ infection in four urban African populations. AIDS 2001;15(Suppl 4):S97-108.

49 Morison L, Weiss HA, Buve A, et al. Commercial sex and the spread of HIV in four cities in sub-Saharan Africa. AIDS 2001;15(Suppl 4):S61-9.

50 Lowndes $\mathrm{CM}$, Alary M, Meda $\mathrm{H}$, et al. Role of core and bridging groups in the transmission dynamics of HIV and STIs in Cotonou, Benin, West Africa. Sex Transm Infect 2002;78(Suppl 1):i69-77.

51 Freeman EE, Glynn JR. Factors affecting HIV concordancy in married couples in four African cities. AIDS 2004;18:1715-21. 
conflict with UK guidelines. Their preferred regimen for the treatment of pelvic inflammatory disease is in particular surprising (doxycycline and metronidazole) since it conforms with neither UK nor US guidelines and three studies have now shown it to be inferior to alternative regimens.

Overall Fast facts: sexually transmitted infections is to be recommended with just a few caveats.

Jonathan Ross

\section{CORRECTIONS}

doi: 10.1136/sti.2006.021782.corr 1

There was an error in the August issue of the journal (Dodds JP, Johnson AM, Parry JV, et al.
A tale of three cities: persisting high HIV prevalence, risk behaviour and undiagnosed infection in community samples of men who have sex with men. Sex Transm Infect 2007;83:392-6.) The last sentence on page 2 should read as follows: "All were screened by GACELISA HIV 1 and 2, whose sensitivity and specificity had been determined as $99.5 \%$ (95\% CI $97.1 \%$ to $99.9 \%$ ) and $99.7 \%$ (95\% CI $98.9 \%$ to $99.9 \%)$, respectively. ${ }^{13} 14$

doi: 10.1136/sti.2006.023283.corr 1

Several errors occurred in an article published in the July issue of the journal (Evans AR, Wiggins RD, Mercer $\mathrm{CH}$, et al. Men who have sex with men in Great Britain: comparison of a self-selected internet sample with a national probability sample. Sex Transm Infect 2007;83:200-5.) A corrected version of the article is available on our website at http:// sti.bmj.com/supplemental.

doi: 10.1136/sti.2006.023531.corr 1

Two articles from the August 2007 supplement were unlocked online but not in print. The articles are: Orroth KK, Freeman EE, Bakker R, et al. Understanding the differences between contrasting HIV epidemics in east and west Africa: results from a simulation model of the Four Cities Study. Sex Transm Infect 2007;83(Suppl 1):i5-i6 and Freeman EE, Orroth KK, White RG, et al. Proportion of new HIV infections attributable to herpes simplex 2 increases over time: simulations of the changing role of sexually transmitted infections in sub-Saharan African HIV epidemics. Sex Transm Infect 2007;83(Suppl 1):il7-i124. Both articles are freely available. 